\title{
COMPARISON OF EFFICACY AND ADVERSE DRUG REACTIONS OF MONOTHERAPY VERSUS COMBINATION THERAPY OF ANTIHYPERTENSIVES AMONG DIABETIC HYPERTENSIVE PATIENTS IN A TERTIARY CARE HOSPITAL
}

\author{
PAULOSE RM ${ }^{1}$, LAXMINARAYANA BAIRY $\mathrm{K}^{1 *}$, PRABHU MM ${ }^{2}$, EESHA BR ${ }^{3}$, VEENA NAYAK ${ }^{1}$, AMRUTA TRIPATHY ${ }^{1}$ \\ ${ }^{1}$ Department of Pharmacology, Kasturba Medical College, Manipal University, Madhav Nagar, Manipal, Karnataka - 576 104, \\ India. ${ }^{2}$ Department of Medicine, Professor in Medicine, Kasturba Medical College, Manipal University, Madhav Nagar, Manipal, \\ Karnataka - 576 104, India. ${ }^{3}$ Department of Pharmacology, Associate Professor in Pharmacology, Kodagu Institute of Medical Sciences, \\ Madikeri, Karnataka - 571 201, India. Email: kl.bairy@manipal.edu
}

Received: 24 October 2016, Revised and Accepted: 03 November 2016

\section{ABSTRACT}

Objective: To compare the efficacy and adverse drug reactions of monotherapy and combination therapy of antihypertensive drugs in diabetic hypertensive patients.

Methods: A prospective observational study of 18 months duration was conducted in the Department of Medicine of a tertiary care hospital in South India. A total of 200 patients were included in the study. Using a standard proforma, the details of patients such as demographic data and antihypertensive medications were collected and analyzed for efficacy and safety.

Results: Of 200 patients studied, 50\% received monotherapy whereas the remaining 50\% received combination therapy. There was male preponderance $(54 \%)$ in the study population, with the mean age being $60.07 \pm 11.32$ years. In monotherapy group, most commonly prescribed drug was amlodipine (38\%), whereas in combination group, angiotensin receptor blocker (ARB) or calcium channel blocker (CCB) + beta blocker (18\%) was commonly prescribed among 2-drug group and ARB+ thiazide+ CCB (25.6\%) among 3-drug group. Monotherapy and combination therapy were analyzed to be equally efficacious in reducing systolic blood pressure and diastolic blood pressure. Based on the adverse effect profile, monotherapy comparatively produced more adverse effects than combination group. Amlodipine-induced pedal edema (56.7\%) was the most common adverse effect observed, and it was predominantly managed by changing it to be a better tolerable CCB, namely cilnidipine.

Conclusion: The combination therapy may be a better treatment option in selected patient population.

Keywords: Systolic blood pressure, Diastolic blood pressure, Amlodipine, Cilnidipine, Pedal edema.

(c) 2017 The Authors. Published by Innovare Academic Sciences Pvt Ltd. This is an open access article under the CC BY license (http://creativecommons. org/licenses/by/4. 0/) DOI: http://dx.doi.org/10.22159/ajpcr.2017.v10i2.15854

\section{INTRODUCTION}

Hypertension (HTN) is one of the most common chronic diseases and is defined as systolic blood pressure (SBP) $\geq 140 \mathrm{~mm} \mathrm{Hg}$ and/or diastolic blood pressure (DBP) $\geq 90 \mathrm{~mm} \mathrm{Hg} \mathrm{[1].} \mathrm{It} \mathrm{exerts} \mathrm{a} \mathrm{considerable}$ health burden on the public regarding its significance in cardiovascular health and thereby the well-being in India [2,3]. HTN is unswervingly accountable for $57 \%$ of all stroke and $24 \%$ of all coronary heart disease (CHD) deaths in India [4] and this correlation is more associated with SBP than with DBP [5]. Globally, it is indeed a vital test in public health due to its high occurrence and related death [6-8].

HTN is a very familiar comorbid state in diabetes wherein approximately $20-60 \%$ of patients with diabetes are affected. HTN extensively intensifies the danger of both macrovascular and microvascular complications, including cerebrovascular disease, CHD, and peripheral vascular disease. Based on convincing data, pharmacological therapy of HTN in patients with diabetes is effective in producing considerable decrease in these complications. The presence of a firm epidemiological relation between HTN in diabetes and undesirable consequences of diabetes has been established, but reduced information from trials evaluating different classes of antihypertensive drugs in patients with HTN associated with diabetes still persists [9]. The intricacy of various pathophysiological processes that lead to rise in BP is such that a judicious and systematic mode of antihypertensive treatment is hardly achievable in any hypertensive patient [10]. However, there are a variety of drugs available for the treatment which can be used alone or in combination to reduce arterial pressure accordingly [11]

The present-day recommendations include a universal approach in controlling HTN, with not much importance given on determining a curative modality based on the various underlying pathophysiology of HTN. Considering the fact that there has been an improved understanding of a specific etiology, it has now become feasible to develop therapies selective for distinct pathophysiological mechanisms with fewer adverse effects, resulting in more effective BP reduction $[12,13]$. Thus, it is considered that with the practice of novel usage of hereditary science unified with an understanding of systemic functioning and population studies, there will be more selective and efficacious methods possible in treating and even averting HTN in the future years $[14,15]$.

Hence, considering the fact that there have been limited data from trials comparing monotherapy and combination therapy of different classes of antihypertensive drugs in patients with diabetes and HTN, the present study was planned to assess the efficacy and adverse effects of monotherapy and combination therapy of antihypertensive drugs among diabetic hypertensive patients.

\section{METHODS}

This prospective observational study was conducted in the Department of Medicine of a tertiary care hospital in South India for 18 months ( $1^{\text {st }}$ November 2013 to $30^{\text {th }}$ April 2015). The Institutional Ethics 
Committee (IEC) clearance was obtained before initiation of the study (letter no. IEC 513/2013). A total of 200 diabetic hypertensive patients fitting into the subject selection criteria were included in the study. They were broadly divided into two treatment groups that included monotherapy and combination therapy groups wherein combination was further divided into 2-drug and 3-drug combination groups; hence, Group 1 is monotherapy, Group 2 is 2-drug, and Group 3 is 3-drug combination group. Subject selection criteria were as follows:

\section{Inclusion criteria}

1. Patient of either male or female sex and age group of $18-80$ years diagnosed with diabetic HTN

2. Diabetic hypertensive patients with comorbidities such as stroke and myocardial infarction.

\section{Exclusion criteria}

1. Patients diagnosed to have chronic kidney diseases (having creatinine values $>2 \mathrm{mg} / \mathrm{dL}$ ), peripheral vascular diseases, and respiratory comorbidities.

2. Patients on steroid medications.

3. Pregnant and lactating mothers.

Patients (outpatients) fulfilling the study criteria were included after obtaining consent and were reviewed for efficacy and adverse drug reaction (ADR) of the prescribed drugs.

1. Demographic and clinical data of each patient (age, sex, and available laboratory reports) were collected.

2. Efficacy of monotherapy and combination therapy of antihypertensive drugs was compared.

- Baseline value was obtained based on patient's initial visit before treatment.

- Two follow-up BP values were noted following the initiation of treatment (ideally, at $4^{\text {th }}$ and $8^{\text {th }}$ week after starting treatment).

- The percentage decrease in SBP and DBP observed over a period of 2 follow-up visits was thereby assessed for efficacy using the following formula.

Percentage reduction in $\mathrm{BP}=\frac{\begin{array}{l}\text { Baseline } \mathrm{BP}-\text { Second follow up } \\ \text { visit reading }(\text { at end of study })\end{array}}{\text { Baseline }} \times 100$

3. The details of suspected ADRs were documented in a suitably designed Central Drugs Standard Control Organization suspected ADR form. Causality assessment was done using the World Health Organization-Uppsala Monitoring Centre (WHO-UMC) causality assessment system [16].

\section{Statistical analysis}

Demographic data were analyzed using descriptive statistics. For efficacy parameter, the mean percentage reduction in BP from baseline to the end of the study (at $2^{\text {nd }}$ follow-up visit) was calculated for individual drugs and combinations in all the three groups. Mean SBP and DBP before and after treatment within each group was compared using paired t-test. Mixed design analysis of variance (ANOVA) model was used to compare SBP and DBP between the groups. $\mathrm{p}<0.05 \%$ was considered statistically significant. ADRs were analyzed using descriptive approach. Data were analyzed using SPSS software version 16 .

\section{RESULTS}

A total of 200 outpatients having HTN associated with diabetes, based on the subject selection criteria, were enrolled and analyzed for demographic characteristics, drug utilization pattern, efficacy analysis of treatment group, and ADR due to prescribed drugs.

Patients were divided eventually into three groups depending on the treatment they received as shown in Table 1 . The mean age of patients in the study population was $60.07 \pm 11.32$ years. They were divided into different age groups (Fig. 1). The majority of the patients were in the $60-69$ years age group (32\%) followed by $50-59$ years age group (28\%). There was a male predominance (54\%) in the study population (Fig. 2).
As shown in Table 2, among all the 100 patients receiving monotherapy, most of the patients received amlodipine (38\%) followed by enalapril (23\%). The least prescribed drug among patients receiving monotherapy was clonidine (4\%). In Group 2 containing 61 patients, the most commonly prescribed combinations were beta blocker + calcium channel blocker (CCB) and angiotensin receptor blocker (ARB) + CCB (18\%) as shown in Table 3. Moreover, among Group 3 that comprised 39 patients, the most commonly prescribed combination group was ARB + thiazide + CCB $(25.6 \%)$ as shown in Table 4

The percentage reduction in SBP among monotherapy group is shown in Table 5. The highest reduction was seen in metoprolol group (16.8\%)

Table 1: Group-wise distribution of patients

\begin{tabular}{ll}
\hline Drug group & Number of patients $(\mathbf{n}=\mathbf{2 0 0})$ \\
\hline Group 1 (monotherapy) & 100 \\
Group 2 (2 drug combination) & 61 \\
Group 3 (3 drug combination) & 39 \\
\hline
\end{tabular}

Table 2: Drug utilization pattern in monotherapy group

\begin{tabular}{ll}
\hline Drug name & Number of patients (\%) \\
\hline Amlodipine & $38(38)$ \\
Enalapril & $23(23)$ \\
Cilnidipine & $16(16)$ \\
Metoprolol & $09(9)$ \\
Prazosin & $05(5)$ \\
Telmisartan & $05(5)$ \\
Clonidine & $04(4)$ \\
\hline
\end{tabular}

ACE: Angiotensin-converting enzyme, CCB: Calcium channel blocker, ARB: Angiotensin receptor blocker

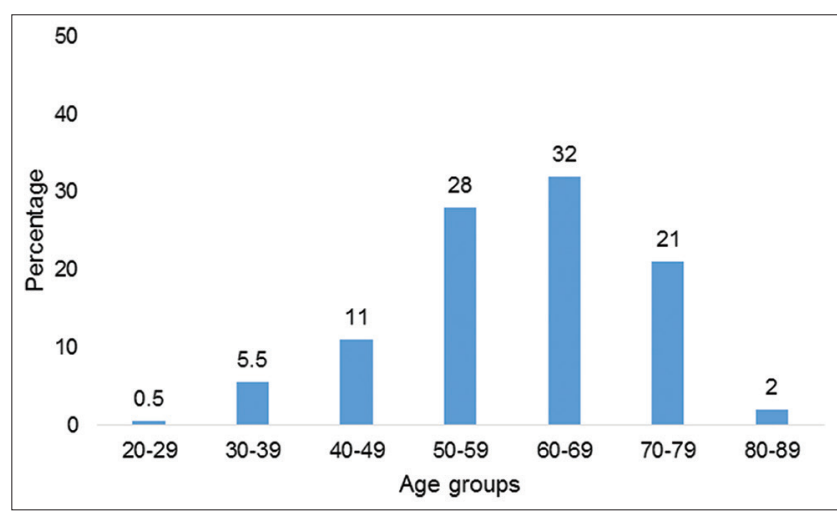

Fig. 1: Age group distribution of patients

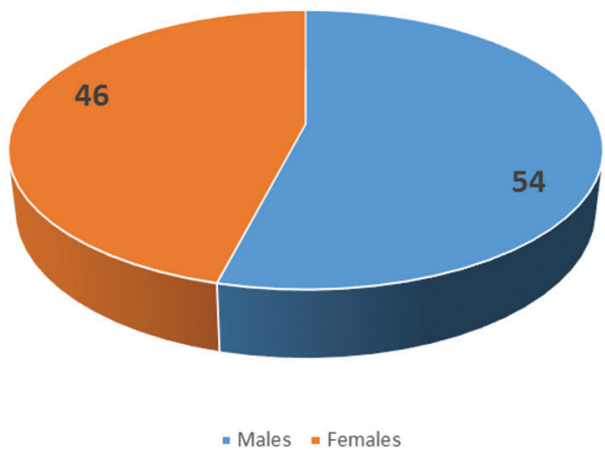

Fig. 2: Gender distribution of patients in percentage 
followed by enalapril group and the least reduction was seen in the telmisartan group (12.6\%). All the medications in Group 1 brought about a statistically significant reduction in percentage decrease in SBP. As shown in Table 6, patients treated with cilnidipine showed the highest reduction in DBP (15.1\%) followed by amlodipine (12.8\%). Least reduction in DBP was seen in prazosin group $(11.1 \%)$ which was not statistically significant. All the other drugs in the monotherapy group showed a statistically significant decrease in DBP. In Group 2, angiotensin-converting enzyme (ACE) inhibitor + CCB combination showed the greatest reduction in SBP $(15.6 \%)$ followed by alpha agonist + CCB combination (15.3\%). Least reduction in SBP was seen in thiazide + CCB combination (11.8\%). The percentage reduction in SBP was statistically significant in all the combinations in Group 2 as shown in Table 7. ARB or beta blocker + CCB combination showed the maximum percentage reduction in DBP $(12.5 \%)$ followed by ACE inhibitor + CCB combination (11.9\%). The least reduction was observed in thiazide + CCB group. The reduction was statistically significant with all the drug combinations as shown in Table 8. As shown in Table 9, in Group 3, there was a comparatively higher percentage reduction in SBP seen in the ARB + CCB + alpha agonist group (17.1\%), the least being in the ACE inhibitor + CCB + alpha agonist group (9.6\%). All the results were statistically significant. As shown in Table 10 , ARB + thiazide + CCB (14.4\%) combination showed greater percentage decrease in DBP with the least decrease seen in ACE inhibitor + CCB + alpha agonist $(11.6 \%)$ combination. The reduction was statistically significant with all the combinations. The fall in SBP and DBP, when compared to the three groups, at baseline and 1 and 2 months, was not statistically significant as per the analysis done using mixed design ANOVA (Figs. 3 and 4).

Table 3: Drug utilization pattern in 2-drug combination group

\begin{tabular}{ll}
\hline Drugs & Number of patients (\%) \\
\hline ACE inhibitor+CCB & $10(16.4)$ \\
Alpha agonist+CCB & $10(16.4)$ \\
Beta blocker+CCB & $11(18.0)$ \\
ARB+CCB & $11(18.0)$ \\
Thiazide+CCB & $08(13.2)$ \\
Others* & $11(18.0)$ \\
\hline
\end{tabular}

CCB: Calcium channel blocker, ARB: Angiotensin receptor blocker, *0thers represent ARB+alpha ${ }_{2}$ agonist, ACE inhibitors+Alpha ${ }_{2}$ agonist, loop diuretics+CCB etc., ACE: Angiotensin-converting enzyme

Table 4: Drug utilization pattern in 3 drug combination group

\begin{tabular}{ll}
\hline Drugs & Number of patients(\%) \\
\hline ARB+thiazide+CCB & $10(25.6)$ \\
ACE inhibitor+CCB+alpha agonist & $09(23.1)$ \\
ARB+CCB+alpha agonist & $09(23.1)$ \\
Others* & $11(28.2)$ \\
\hline
\end{tabular}

CCB: Calcium channel blocker, ARB: Angiotensin receptor blocker, *0thers represent $\beta$-blocker+alpha blocker+alpha ${ }_{2}$ agonist, beta blocker+thiazide+alpha blocker etc., ACE: Angiotensin-converting enzyme
As shown in Tables 11-14, of 200 patients, 30 (15\%) patients developed ADRs. Most of the drug reactions were seen in the monotherapy group (66.7\% of the total ADRs). Rest of the ADRs were seen among the combination groups (33.3\% of total ADRs). Amlodipine-induced pedal edema was the most common ADR among the three groups (56.7\%). All ADRs were classified as "possible" according to WHO-UMC causality assessment scale.

\section{DISCUSSION}

The present study suggested that most of the patients (32\%) having HTN associated with diabetes belong to age group of 60-69 years followed by $28 \%$ belonging to the age group of $50-59$ years; the mean age of the study population was $60.07 \pm 11.32$ years. The least percentage of patients $(0.5 \%)$ was seen in 20-29 years age group. Supporting this, according to Everett et al., the incidence of HTN was more commonly seen in patients below 65 years $(85.9-87.7 \%)$ in comparison to patients above 65 years (12.3-14.0\%) [17]. Lacourciere et al. [18] and Ruilope et al. levels [19] had also been consistent with the current study showing the mean age to be 60-61 years; however; in a study carried out by Yasmeen et al., $31.7 \%$ patients belonged to 51 60 years age group followed by $28.9 \%$ in $41-50$ years age group with the least (3.5\%) being 71-80 years age group [20]. The rationale for an increase in blood pressure with age could probably be due to structural changes in the arteries and especially with large artery stiffness [21].

In the present study, there was male preponderance in patients having HTN with diabetes (54\%). Previous studies conducted in India (Yasmeen et al., Jaganan et al.), USA (Everett et al.), Nepal (Pandaya et al.), and Australia (White et al.) have also reported that the incidence of HTN with diabetes mellitus was higher in males compared to females $[17,20,22-24]$. This could probably be due to significantly higher awareness, treatment, and control rates among women than men as supported by a recent data from the 2007 to 2010 National Health and Nutrition Examination Survey [25].

The most common groups of antihypertensive drugs such as CCBs, beta blockers, ACE inhibitors, ARBs, alpha blockers, alpha agonists, and diuretics were used to treat HTN in the present study. Among these, the most frequently used antihypertensive as monotherapy was amlodipine (38\%) followed by enalapril (23\%). Alavudeen et al. showed similar finding wherein the most commonly prescribed drug among monotherapy was CCB $(34.3 \%)$ followed by ACE inhibitors (29.9\%) [26]. This was also seen by Kousalya et al., where amlodipine $(83.8 \%)$ was the most commonly used drug [27]. Diuretics were not prescribed as a monotherapy in this study, which was different from studies done by Tamuno and Fadare and Etuk et al. wherein diuretics were the regularly prescribed drug $(41.2 \%$ and $44.8 \%$, respectively) as monotherapy $[28,29]$. However, according to the WHO guidelines, ACE inhibitors are ideally regarded as the favored therapy in patients with HTN and diabetes [30]. Findings from the heart outcomes prevention evaluation study also support the above guidelines [31]. According to Bronsert et al., Kaur et al., Jaganan et al., and Beulah et al., the most commonly prescribed class of drug was ACE inhibitor (43.6\%, 33.8\%, 52.3\%, and 56.7\%, respectively) [22,32-34].

Table 5: Effect of monotherapy on systolic blood pressure $(n=100)$

\begin{tabular}{|c|c|c|c|c|c|}
\hline \multirow[t]{2}{*}{ Drugs } & \multicolumn{2}{|l|}{ Systolic BP (mm HG) } & \multirow{2}{*}{$\begin{array}{l}\text { Mean decrease in } \\
\text { SBP (mm HG) }\end{array}$} & \multirow{2}{*}{$\begin{array}{l}\text { Percentage decrease } \\
\text { in SBP }\end{array}$} & \multirow[t]{2}{*}{$\mathbf{p}$} \\
\hline & Baseline (mean $\pm S D$ ) & After (mean \pm SD) & & & \\
\hline Amlodipine & $162.6 \pm 11.0$ & $137.2 \pm 13.3$ & $25.4 \pm 4.2$ & 15.6 & $<0.001^{*}$ \\
\hline Cilnidipine & $159.6 \pm 7.4$ & $133.7 \pm 8.8$ & $25.8 \pm 5.6$ & 16.2 & $<0.001^{*}$ \\
\hline Metoprolol & $160.0 \pm 8.6$ & $133.1 \pm 12.9$ & $26.8 \pm 11.9$ & 16.8 & $<0.001^{*}$ \\
\hline Prazosin & $160.0 \pm 7.0$ & $138.0 \pm 8.3$ & $22.0 \pm 4.4$ & 13.7 & $<0.001^{*}$ \\
\hline Telmisartan & $162.0 \pm 8.3$ & $141.6 \pm 2.1$ & $20.4 \pm 6.5$ & 12.6 & $<0.05^{*}$ \\
\hline Clonidine & $155.0 \pm 5.7$ & $132.5 \pm 12.5$ & $22.5 \pm 9.5$ & 14.5 & $<0.05^{*}$ \\
\hline
\end{tabular}

SD: Standard deviation, SBP: Systolic blood pressure, $\mathrm{mm} \mathrm{Hg}$ is Millimeter of mercury, SD is standard deviation for $\mathrm{n}=100$ observations. ${ }^{*}$ represents statistical significance 


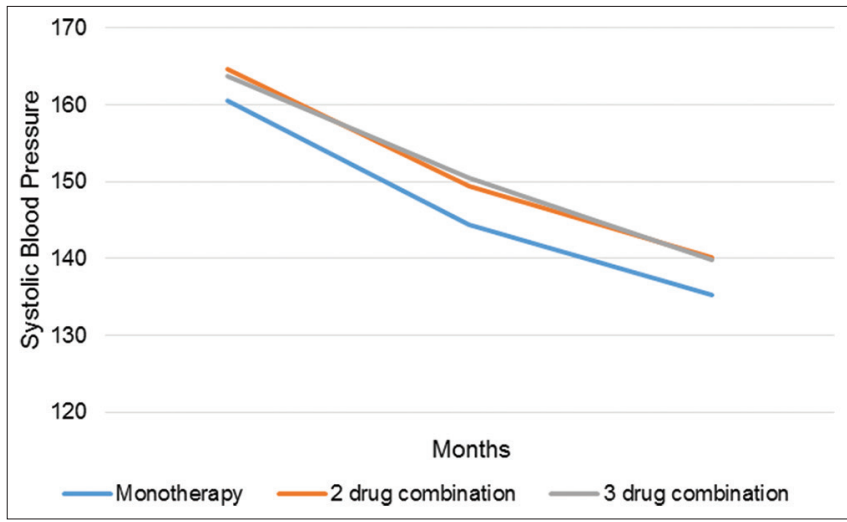

Fig. 3: Comparison of fall in systolic blood pressure between monotherapy and combination group

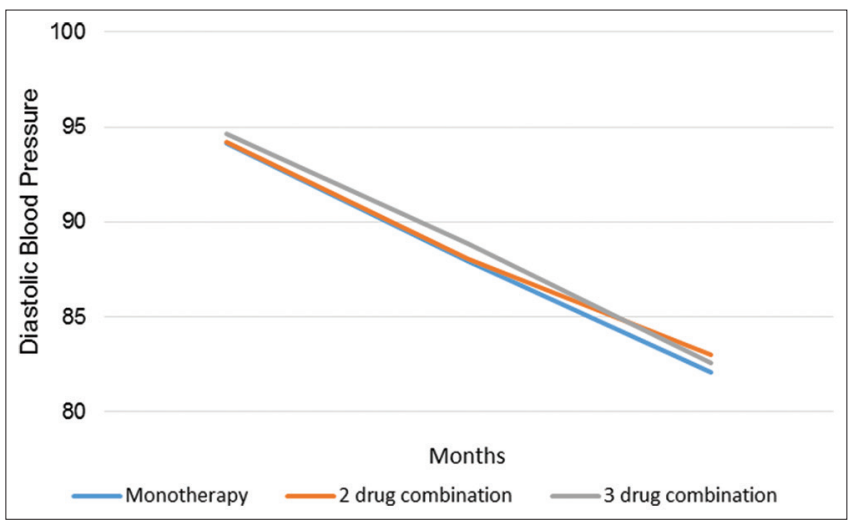

Fig. 4: Comparison of fall in diastolic blood pressure between monotherapy and combination group

Table 6: Effect of monotherapy on diastolic blood pressure $(n=100)$

\begin{tabular}{|c|c|c|c|c|c|}
\hline \multirow[t]{2}{*}{ Drugs } & \multicolumn{2}{|l|}{ Diastolic BP (mm HG) } & \multirow{2}{*}{$\begin{array}{l}\text { Mean decrease in } \\
\text { DBP (mm HG) }\end{array}$} & \multirow{2}{*}{$\begin{array}{l}\text { Percentage decrease } \\
\text { in DBP }\end{array}$} & \multirow[t]{2}{*}{$\mathbf{p}$} \\
\hline & Baseline (mean \pm SD) & After (mean $\pm S D)$ & & & \\
\hline Amlodipine & $95.4 \pm 9.3$ & $83.2 \pm 7.1$ & $12.2 \pm 6.2$ & 12.8 & $<0.001^{*}$ \\
\hline Enalapril & $95.0 \pm 5.8$ & $83.4 \pm 6.4$ & $11.5 \pm 6.0$ & 12.2 & $<0.001^{*}$ \\
\hline Cilnidipine & $92.0 \pm 6.5$ & $78.1 \pm 6.5$ & $13.8 \pm 6.3$ & 15.1 & $<0.001^{*}$ \\
\hline Metoprolol & $91.1 \pm 7.8$ & $80.0 \pm 5.0$ & $11.1 \pm 6.0$ & 12.2 & $<0.05^{*}$ \\
\hline Prazosin & $90.0 \pm 7.0$ & $80.0 \pm 7.0$ & $10.0 \pm 10.0$ & 11.1 & 0.089 \\
\hline Clonidine & $95.0 \pm 5.7$ & $84.0 \pm 4.8$ & $11.0 \pm 2.0$ & 11.6 & $<0.05^{*}$ \\
\hline
\end{tabular}

SD: Standard deviation, DBP: Diastolic blood pressure, $\mathrm{mm}$ Hg is Millimeter of mercury, SD is standard deviation for $\mathrm{n}=100$ observations. ${ }^{*}$ represents statistical significance

Table 7: Effect of 2 drug combination on systolic blood pressure $(n=61)$

\begin{tabular}{llllll}
\hline Drugs & \multicolumn{2}{l}{ Systolic BP (mm HG) } & & $\begin{array}{l}\text { Mean decrease in } \\
\text { SBP (mm HG) }\end{array}$ & $\begin{array}{l}\text { Percentage decrease } \\
\text { in SBP }\end{array}$ \\
\cline { 2 - 3 } & Baseline (mean \pm SD) & After (mean \pm SD) & & \\
\hline ACE inhibitor+CCB & $162.4 \pm 4.1$ & $137.0 \pm 11.5$ & $25.4 \pm 9.5$ & 15.6 & $<0.001^{*}$ \\
Alpha agonist+CCB & $184.6 \pm 13.5$ & $156.2 \pm 11.6$ & $28.4 \pm 6.9$ & 15.3 & $<0.001^{*}$ \\
Beta blocker+CCB & $159.8 \pm 6.0$ & $137.0 \pm 8.2$ & $22.7 \pm 8.0$ & 14.2 & $<0.001^{*}$ \\
ARB+CCB & $165.5 \pm 12.1$ & $140.3 \pm 11.8$ & $25.0 \pm 9.6$ & 15.2 & $<0.001^{*}$ \\
Thiazide+CCB & $155.0 \pm 5.3$ & $136.7 \pm 6.4$ & $18.2 \pm 8.2$ & 11.8 & $<0.001^{*}$ \\
Others & $160.0 \pm 7.7$ & $134.0 \pm 10.1$ & $26.0 \pm 10.7$ & 16.2 & $<0.001^{*}$ \\
\hline
\end{tabular}

SD: Standard deviation, SBP: Systolic blood pressure, CCB: Calcium channel blocker, ARB: Angiotensin receptor blocker, mm Hg is Millimeter of mercury, SD is standard deviation for $\mathrm{n}=61$ observations, ${ }^{*}$ represents statistical significance, ACE: Angiotensin-converting enzyme

Table 8: Effect of 2-drug combination on diastolic blood pressure $(n=61)$

\begin{tabular}{|c|c|c|c|c|c|}
\hline \multirow[t]{2}{*}{ Drugs } & \multicolumn{2}{|l|}{ Diastolic BP (mm HG) } & \multirow{2}{*}{$\begin{array}{l}\text { Mean decrease in } \\
\text { DBP ( } \mathrm{mm} \mathrm{HG} \text { ) }\end{array}$} & \multirow{2}{*}{$\begin{array}{l}\text { Percentage decrease } \\
\text { in DBP }\end{array}$} & \multirow[t]{2}{*}{$\mathbf{p}$} \\
\hline & Baseline (mean \pm SD) & After (mean \pm SD) & & & \\
\hline ACE inhibitor+CCB & $92.0 \pm 9.1$ & $81.0 \pm 7.3$ & $11.0 \pm 5.6$ & 11.9 & $<0.001^{*}$ \\
\hline Alpha agonist+CCB & $98.4 \pm 6.0$ & $88.0 \pm 4.2$ & $10.4 \pm 3.6$ & 10.5 & $<0.001^{*}$ \\
\hline Beta blocker+CCB & $94.5 \pm 5.2$ & $82.7 \pm 6.4$ & $11.8 \pm 6.0$ & 12.5 & $<0.001^{*}$ \\
\hline $\mathrm{ARB}+\mathrm{CCB}$ & $96.7 \pm 8.8$ & $84.5 \pm 6.8$ & $12.1 \pm 6.6$ & 12.5 & $<0.001^{*}$ \\
\hline Thiazide+CCB & $91.2 \pm 3.5$ & $83.0 \pm 4.5$ & $8.2 \pm 3.6$ & 9.0 & $<0.001^{*}$ \\
\hline Others & $91.8 \pm 6.0$ & $79.0 \pm 7.0$ & $12.7 \pm 7.8$ & 13.8 & $<0.001^{*}$ \\
\hline
\end{tabular}

SD: Standard deviation, CCB: Calcium channel blocker, ARB: Angiotensin receptor blocker, $\mathrm{mm}$ Hg is Millimeter of mercury, SD is standard deviation for $\mathrm{n}=100$

observations, *represents statistical significance, ACE: Angiotensin-converting enzyme

It was seen in the current study that majority of the patients received beta blocker + CCB (18\%) and ARB + CCB (18\%) among the 2-drug combination group. This is in agreement with the study conducted by Panda et al., wherein the most common 2-drug combination prescribed was CCB+ beta blocker (30.3\%) followed by CCB + ARB (25.9\%) [35]. Alavudeen et al. also reported that CCB+ARB (25\%) was the common drug prescribed among the 2-drug combination group [26]. However, most of the other studies had shown an inconsistent finding with the present study in relation to the most common 2-drug combination drugs prescribed. Tamuno and Fadare and Pandaya et al. reported that the most commonly used 2-drug combination was CCB + diuretic (12\% and $37.8 \%$, respectively) [23,28]. According to Kausalya et al., ACE inhibitor + CCB was the most commonly prescribed 2-drug combination, whereas in a study by Jaganan et al., ACE inhibitors 
Table 9: Effect of 3-drug combination on systolic blood pressure ( $n=39)$

\begin{tabular}{|c|c|c|c|c|c|}
\hline \multirow[t]{2}{*}{ Drugs } & \multicolumn{2}{|l|}{ Systolic BP (mm HG) } & \multirow{2}{*}{$\begin{array}{l}\text { Mean decrease in } \\
\text { SBP (mm HG) }\end{array}$} & \multirow{2}{*}{$\begin{array}{l}\text { Percentage decrease } \\
\text { in SBP }\end{array}$} & \multirow[t]{2}{*}{$\mathbf{p}$} \\
\hline & Baseline (mean $\pm \mathrm{SD}$ ) & After $($ mean \pm SD) & & & \\
\hline ACE inhibitor+CCB+Alpha agonist & $166.6 \pm 5.0$ & $150.6 \pm 5.0$ & $16.0 \pm 3.8$ & 9.6 & $<0.001^{*}$ \\
\hline $\mathrm{ARB}+$ thiazide+CCB & $162.0 \pm 7.8$ & $135.0 \pm 9.7$ & $27.0 \pm 4.8$ & 16.7 & $<0.001^{*}$ \\
\hline $\mathrm{ARB}+\mathrm{CCB}+$ Alpha agonist & $164.0 \pm 6.6$ & $136.0 \pm 5.3$ & $28.0 \pm 7.2$ & 17.1 & $<0.001^{*}$ \\
\hline Others & $162.9 \pm 4.5$ & $138.5 \pm 6.0$ & $24.3 \pm 5.1$ & 14.9 & $<0.001^{*}$ \\
\hline
\end{tabular}

SD: Standard deviation, CCB: Calcium channel blocker, ARB: Angiotensin receptor blocker, SBP: Systolic blood pressure, mm Hg is Millimeter of mercury, SD is standard deviation for $n=39$ observations, *represents statistical significance, ACE: Angiotensin-converting enzyme

Table 10: Effect of 3-drug combination on diastolic blood pressure ( $n=39)$

\begin{tabular}{|c|c|c|c|c|c|}
\hline \multirow[t]{2}{*}{ Drugs } & \multicolumn{2}{|l|}{ Diastolic BP (mm HG) } & \multirow{2}{*}{$\begin{array}{l}\text { Mean decrease in } \\
\text { DBP ( } \mathrm{mm} \mathrm{HG})\end{array}$} & \multirow{2}{*}{$\begin{array}{l}\text { Percentage decrease } \\
\text { in DBP }\end{array}$} & \multirow[t]{2}{*}{$\mathbf{p}$} \\
\hline & Baseline (mean \pm SD) & After $($ mean \pm SD) & & & \\
\hline ACE inhibitor+CCB+Alpha agonist & $95.5 \pm 5.2$ & $84.4 \pm 5.2$ & $11.1 \pm 3.3$ & 11.6 & $<0.001^{*}$ \\
\hline $\mathrm{ARB}+$ thiazide+CCB & $97.0 \pm 6.7$ & $83.0 \pm 6.7$ & $14.0 \pm 6.9$ & 14.4 & $<0.001^{*}$ \\
\hline $\mathrm{ARB}+\mathrm{CCB}+\mathrm{Alpha}$ agonist & $95.5 \pm 7.2$ & $82.2 \pm 4.4$ & $13.3 \pm 5.0$ & 13.9 & $<0.001^{*}$ \\
\hline Others & $90.9 \pm 5.3$ & $80.9 \pm 5.3$ & $10.0 \pm 6.3$ & 11.1 & $<0.001^{*}$ \\
\hline
\end{tabular}

SD: Standard deviation, CCB: Calcium channel blocker, ARB: Angiotensin receptor blocker, DBP: Diastolic blood pressure, mm Hg is Millimeter of mercury, SD is standard deviation for $\mathrm{n}=39$ observations, ${ }^{*}$ represents statistical significance, ACE: Angiotensin-converting enzyme

Table 11: Group-wise ADR analysis

\begin{tabular}{ll}
\hline Drug group & Number of ADRs (n=30) \\
\hline Monotherapy & $20(66.7)$ \\
2-drug combination & $06(20.0)$ \\
3-drug combination & $04(13.3)$ \\
\hline
\end{tabular}

ADR: Adverse drug reaction

Table 12: Drug-wise adverse drug reaction analysis

\begin{tabular}{lll}
\hline Drug name & ADR & $\mathbf{n = 3 0}$ \\
\hline Amlodipine & Pedal edema & $17(56.7)$ \\
Enalapril & Dry cough & $05(16.7)$ \\
& Acute kidney injury & $01(3.3)$ \\
Telmisartan & Dry cough & $02(6.7)$ \\
& Hyponatremia & $01(3.3)$ \\
Hydrochlorothiazide & Hyperkalemia & $01(3.3)$ \\
& Hypokalemia & $03(10.0)$ \\
\hline
\end{tabular}

ADR: Adverse drug reaction

Table 13: Adverse drug reactions in monotherapy group

$\left.\begin{array}{lll}\hline \text { Drug } & \text { ADR } & \text { Number of ADRs (n=20) } \\ \hline \text { Amlodipine } & \text { Pedal edema } & 13(65 \%) \\ \text { Enalapril } & \text { Dry cough } & 03 \\ & & \\ & \text { Acute kidney injury } & 01\end{array}\right](20 \%)$

ADR: Adverse drug reaction

with thiazide diuretics $(34.3 \%)$ were the most commonly prescribed combination $[22,27]$.

In the present study, the most commonly prescribed 3-drug combination was $\mathrm{ARB}+$ thiazide+ $\mathrm{CCB}(25.6 \%)$ followed by an equal percentage of $23.1 \%$ for ACE inhibitor+ $\mathrm{CCB}+$ alpha agonist and $\mathrm{ARB}+\mathrm{CCB}+$ alpha agonist. Similarly, Alavudeen et al. reported that $\mathrm{ARB}+\mathrm{CCB}+$ diuretic
(21.4\%) was the most commonly used 3-drug combination [26]. Panda et al. had also shown ARB+ thiazide+ CCB (1.9\%) as the most common 3-drug combination prescribed, hence showing consistency [35]. According to Tamuno and Fadare and Kousalya et al., ACE inhibitor + diuretic + CCB (14.5\% and 34.4\%, respectively) was commonly used in the 3-drug combination group $[27,28]$. However, according to Etuk et al., inclusion of alpha methyldopa in the 3-drug combination therapy was found to be more common in the form of alpha methyldopa + ACE inhibitor + diuretic combination (17.2\%) [29]. This was different from the present study wherein clonidine was the most frequently used alpha agonist used in combination with CCB and ARB or ACE inhibitor (23\%).

We found that, among the monotherapy group, metoprolol showed maximum percentage reduction in SBP (16.8\%) followed by a reduction of $16.6 \%$ seen in the enalapril group. This finding was supported by another study conducted by Beulah s et al. wherein beta blockers produced a greater percentage reduction of $31.1 \%$ followed by a $28.5 \%$ reduction seen in ACE inhibitors [34]. However, in a study conducted by Yasmeen et al., enalapril showed greater percentage reduction in SBP (18.8\%) followed by $14.1 \%$ reduction in atenolol [20]. In relation to DBP, maximum percentage reduction was seen in the CCB group where the novel calcium antagonist cilnidipine produced $15.1 \%$ reduction followed by $12.8 \%$ reduction seen in amlodipine. This was supported by Etuk et al. where CCB monotherapy had shown to be effective in reduction of DBP (13.4\%) [29]. However, in other studies where beta blockers and ACE inhibitors were predominantly used as monotherapy, beta blockers produced comparatively greater percentage decrease in DBP (15.1\% and 18.3\%, respectively) than ACE inhibitors (14.9\% and $15.9 \%$, respectively) $[20,34]$.

Among the 2-drug combination group, we observed greater percentage reduction in SBP (15.6\%) with ACE inhibitor + CCB group. This finding was consistent with earlier studies wherein the ACE inhibitor + CCB group showed a greater percentage reduction (21.8\%) in comparison to the other 2-drug combination groups [20,36-38]. In our study, we found a greater percentage decrease in DBP with ARB + CCB and beta blocker + CCB group (12.5\%). According to Chrysant et al., ARB + CCB combination has shown to be effective [39]. A retrospective cohort study by Bisognano et al. showed that beta blocker + CCB group was more effective than beta blocker + ACE inhibitor and beta blocker + ARB combination as it had produced a $9.4 \%$ reduction in DBP [40]. However, in other studies such as Yasmeen et al. and Beulah et al., CCB + diuretic group had shown a greater reduction in DBP of $17.7 \%$ and $18.8 \%$, respectively $[20,34]$. 
Table 14: Adverse drug reactions in combination groups

\begin{tabular}{lll}
\hline $\mathbf{2}$ Drug combination & & \\
\hline Combination & Implicated drug & Adverse drug reaction \\
\hline CCB+Thiazide & Thiazide & Hypokalemia \\
ARB+Thiazide & Amlodipine & Pumber of ADRs (n=6) \\
ARB+CCB & & Pedal edema \\
ACE inhibitor+CCB & Enalapril & \\
ACE inhibitor+CCB & Amlodipine & Dry cough \\
ARB+Thiazide+CCB & & Pedal edema \\
$\begin{array}{l}\text { D Drug combination } \\
\text { Combination }\end{array}$ & Implicated drug & Adverse drug reaction \\
ACE inhibitor+beta blocker+alpha blocker & Enalapril & Dry cough \\
ARB+thiazide+alpha blocker & Telmisartan & Dry cough \\
\hline
\end{tabular}

CCB: Calcium channel blocker, ARB: Angiotensin receptor blocker, ADR: Adverse drug reaction, ACE: Angiotensin-converting enzyme

In the present study, among the 3-drug combination group, $\mathrm{ARB}+\mathrm{CCB}+$ alpha agonist had shown a greater percentage decrease in SBP (17.1\%) whereas ARB+ thiazide+ CCB (14.4\%) showed the best reduction in DBP. Maladkar et al. and Oparil et al. had shown the superiority of ARB+ thiazide+ CCB triple combination for control of DBP [41,42]. However, in the study by Yasmeen et al., beta blocker+ CCB+ ACE inhibitor produced maximum percentage decrease in SBP and DBP $(16.6 \%$ and $29.2 \%$, respectively), whereas according to Beulah et al., ACE inhibitor + beta blocker + diuretic led to a greater percentage decrease in both SBP and DBP (39\% and $18.3 \%)[20,34]$.

Upon comparison of efficacy between monotherapy and combination therapy of antihypertensives, it was seen that both were equally effective. Consistent with above findings, Yasmeen et al. had shown that all groups in monotherapy and combination therapy were equally effective in reducing BP [20]. Similarly, Beulah et al. also supported the present study with the same findings [34]. However, according to a meta-analysis conducted by Wald et al. on 11,000 patients from 42 trials, combination of antihypertensive drugs from various classes is approximately 5 times more efficient than a 2 -fold increase in the dose of one drug [43]. This could be due to synergistic action of individual antihypertensive drugs upon combination.

As shown in results, $15 \%$ of patients developed ADRs and most of the ADRs were seen in the monotherapy group (66.7\%). However, according to Husain et al., combination therapy had shown drastically higher occurrence of ADRs of $61.8 \%$ as compared to monotherapy showing $38.2 \%$ of drug reactions [44]. This could probably be due to summation or additive effect of individual drugs in relation to their adverse effects when used as combination. Among the monotherapy group, amlodipine-induced pedal edema was the most common ADR noted $(56.7 \%)$ followed by enalapril-induced dry cough (16.7\%). This finding was supported by Beulah et al., where the most common adverse effect observed was amlodipine-induced pedal edema (22\%) and the second most common adverse reaction was ACE inhibitor-induced dry cough (10\%) [34]. The relatively lower incidence of pedal edema in the CCB-thiazide groups as compared to CCB monotherapy could be attributed to the diuretic action of thiazides. Moreover, the incidence of adverse effects was more commonly seen in the amlodipine group possibly because it was the most common drug prescribed in the present study. Other adverse effects noted were electrolyte imbalances such as hyponatremia, hypokalemia, and hyperkalemia. No serious ADRs were observed in our study.

According to modified Hartwig severity scale, all ADRs were mild to moderate in severity which was managed by either reduction in dosage or frequency or change in the suspected drug, reduced dosage, or change in the drug [45]. According to the WHO causality assessment system, all these ADRs were classified as 'possible' because all ADRs occurred in relation to the time of drug intake, but which could be justified by other coexisting diseases or drugs [16].
Non-pharmacological therapy which includes alterations in the standard of living can reduce and thereby aid in BP adjustment. These prove to be appreciable when applied in support to drug therapy. It can play a critical role in controlling BP by improving the effectiveness of antihypertensive drugs, reducing the risks associated with the cardiovascular system, and also decrease the amount of drugs required or their dosage. Weight reduction in overweight or obese individuals [46], implementation of DASH eating plan rich in potassium, calcium, and dietary sodium reduction, and regular exercises [47-49] are some of the variations in daily life that have shown improved outcomes in BP reduction.

The major limitation of this study was the shorter duration of the study period. All patients were followed up for only 8 weeks. A longer duration of the study would have been helpful in a better understanding of the efficacy and tolerability of the drugs as it would have been essential in the better assessment of the various long-term cardiovascular and mortality outcomes. Hence, patients have to be followed for a longer period to evaluate the efficacy and tolerability of the drugs.

\section{CONCLUSION}

Though monotherapy and combination therapy were equally effective with the latter producing fewer ADRs, combination therapy may be considered as a better treatment option in selected patient population. However, further studies of longer duration are required to determine the long-term benefits of various antihypertensive medications used as both monotherapy and combination therapy for this chronic and diverse health problem.

\section{REFERENCES}

1. Egan BM, Zhao Y. Different definitions of prevalent hypertension impact: The clinical epidemiology of hypertension and attainment of healthy people goals. J Clin Hypertens (Greenwich) 2013;15(3):154-61.

2. Anchala R, Kannuri NK, Pant H, Khan H, Franco OH, Di Angelantonio E, et al. Hypertension in India: A systematic review and meta-analysis of prevalence, awareness, and control of hypertension. J Hypertens 2014;32(6):1170-7

3. Srinath Reddy K, Shah B, Varghese C, Ramadoss A. Responding to the threat of chronic diseases in India. Lancet 2005;366(9498):1744-9.

4. Gupta R, Gupta VP. Hypertension epidemiology in India: Lessons from Jaipur heart watch. Curr Sci 2009;97(3):349-55.

5. Mourad JJ. The evolution of systolic blood pressure as a strong predictor of cardiovascular risk and the effectiveness of fixed-dose ARB/CCB combinations in lowering levels of this preferential target. Vasc Health Risk Manag 2008;4(6):1315-25.

6. Bromfield S, Muntner P. High blood pressure: The leading global burden of disease risk factor and the need for worldwide prevention programs. Curr Hypertens Rep 2013;15:134-6.

7. Park JB, Kario K, Wang JG. Systolic hypertension: An increasing clinical challenge in Asia. Hypertens Res 2015;38(4):227-36.

8. Danaei G, Finucane MM, Lin JK, Singh GM, Paciorek CJ, Cowan MJ, et al. National, regional, and global trends in systolic blood pressure since 1980: Systematic analysis of health examination surveys and 
epidemiological studies with 786 country-years and 5.4 million participants. Lancet 2011;377(9765):568-77.

9. Rossi GP, Seccia TM, Pessina AC. Secondary hypertension: The ways of management. Curr Vasc Pharmacol 2010;8(6):753-68.

10. Long AN, Dagogo-Jack S. Comorbidities of diabetes and hypertension: Mechanisms and approach to target organ protection. J Clin Hypertens (Greenwich) 2011;13(4):244-51.

11. Volpe M, Tocci G. Challenging hypertension: How to diagnose and treat resistant hypertension in daily clinical practice. Expert Rev Cardiovase Ther 2010;8(6):811-20.

12. Hernandez-Vila E. A review of the JNC 8 blood pressure guideline. Tex Heart Inst J 2015;42:226-8

13. Alhawassi TM, Krass I, Pont LG. Hypertension in older persons: A systematic review of national and international treatment guidelines. J Clin Hypertens (Greenwich) 2015;17(6):486-92.

14. Ash GI, Eicher JD, Pescatello LS. The promises and challenges of the use of genomics in the prescription of exercise for hypertension: The 2013 update. Curr Hypertens Rev 2013;9(2):130-47.

15. Carty DM, Schiffer E, Delles C. Proteomics in hypertension. J Hum Hypertens 2013;27(4):211-6.

16. The Use of the WHO-UMC System for Standardized Case Causality Assessment. Available from: http://www.who-umc.org/Graphics/24734. pdf. [Last cited on 2015 Aug 26].

17. Everett BM, Glynn RJ, Danielson E, Ridker PM. Combination therapy versus monotherapy as initial treatment for stage 2 hypertension: A prespecified subgroup analysis of a community-based, randomized, open-label trial. Clin Ther 2008;30:661-72.

18. Lacourcière Y, Poirier L, Hebert D, Assouline L, Stolt P, Rehel B, et al. Antihypertensive efficacy and tolerability of two fixed-dose combinations of valsartan and hydrochlorothiazide compared with valsartan monotherapy in patients with stage 2 or 3 systolic hypertension: An 8-week, randomized, double-blind, parallel-group trial. Clin Ther 2005;27:1013-21.

19. Ruilope LM, Malacco E, Khder Y, Kandra A, Bönner G, Heintz D. Efficacy and tolerability of combination therapy with valsartan plus hydrochlorothiazide compared with amlodipine monotherapy in hypertensive patients with other cardiovascular risk factors: The VAST study. Clin Ther 2005;27(5):578-87.

20. Yasmeen N, Varma RK, Siddiqua SS, Donepudi A. Efficacy and tolerability of different antihypertensive drugs in patients with mild to moderate hypertension in a tertiary care hospital - A prospective, comparative study. Arch Appl Sci Res 2011;3:436-43.

21. Pinto E. Blood pressure and ageing. Postgrad Med J 2007;83(976):109-14.

22. Janagan T, Kavitha R, Sridevi SA, Veerendra V. Prescription pattern of antihypertensive drugs used in hypertensive patients with associated type 2 diabetes mellitus in a tertiary care hospital. IJPRR 2014;3:1-5.

23. Pandaya S, Reyad-ul-ferdous M, Panthi VK, Pandey M, Maharjan L. Effectiveness of antihypertensive agents among hypertensive patients of Nepal. Int Res J Pharm 2014:5:903-9.

24. White F, Wang L, Jelinek HF. Management of hypertension in patients with diabetes mellitus. Exp Clin Cardiol 2010;15(1):5-8.

25. Doumas M, Papademetriou V, Faselis C, Kokkinos P. Gender differences in hypertension: Myths and reality. Curr Hypertens Rep 2013;15(4):321-30.

26. Alavudeen SS, Alakhali KM, Ansari SMA, Khan NA. Prescribing pattern of antihypertensive drugs in diabetic patients of Southern province, Kingdom of Saudi Arabia. Ars Pharm 2015;56:109-14.

27. Kousalya K, Chirumamilla S, Manjunath S, Ramalakshmi S, Saranya P, Chamundeeswari D. Prescribing trend of antihypertensive drugs in hypertensive and diabetic hypertensive patients. Asian J Pharm Clin Res 2012;5:22-3

28. Tamuno I, Fadare J. Drug treatment for hypertension in a tertiary care facility in Northern Nigeria. Int J Pharm Biomed Res 2011;2:104-9.

29. Etuk E, Isezuo SA, Chika A, Akuche J, Ali M. Prescription pattern of anti-hypertensive drugs in a tertiary health institution in Nigeria. Ann Afr Med 2008;7(3):128-32.

30. Whitworth JA; World Health Organization, International Society of Hypertension Writing Group 2003 World Health Organization (WHO)/ International Society of Hypertension (ISH) statement on management of hypertension. J Hypertens 2003;21(11):1983-92.

31. Sleight P. The HOPE study (Heart Outcomes Prevention Evaluation).
J Renin Angiotensin Aldosterone Syst 2000;1(1):18-20 .

32. Bronsert MR, Henderson WG, Valuck R, Hosokawa P, Hammermeister K. Comparative effectiveness of antihypertensive therapeutic classes and treatment strategies in the initiation of therapy in primary care patients: A Distributed Ambulatory Research in Therapeutics Network (DARTNet) study. J Am Board Fam Med 2013;26(5):529-38.

33. Kaur S, Gupta S, Kumar D, Lal M, Gilani Z. Prescribing pattern of antihypertensive drugs in a tertiary care hospital in Jammu-A descriptive study. JK Pract 2012;17:38-41.

34. Beulah S, Uma MR, Balaji S. Efficacy and tolerability of different antihypertensive drugs in diabetic patients with mild to moderate hypertension in a multi speciality hospital - A prospective comparative study. Indian J Pharm Pract 2012;5(1):21-7.

35. Panda BB, Pati MR, Sahu PK. Survey of prescription pattern of antihypertensive drugs in hypertensive in hypertensive and diabetic hypertensive patients. Asian J Pharm Clin Res 2015;8:250-2.

36. Bainbridge AD, Macfadyen RJ, Stark S, Lees KR, Reid JL. The antihypertensive efficacy and tolerability of a low dose combination of ramipril and felodipine ER in mild to moderate essential hypertension. Br J Clin Pharmacol 1993;36:323-30.

37. Naidu MU, Usha PR, Rao TR, Shobha JC. Evaluation of amlodipine, lisinopril, and a combination in the treatment of essential hypertension. Postgrad Med J 2000;76:350-3

38. Miranda RD, Mion D Jr, Rocha JC, Koglmann O Jr, Gomes MA, Saraiva JF, et al. An 18-week, prospective, randomized, doubleblind, multicenter study of amlodipine/ramipril combination versus amlodipine monotherapy in the treatment of hypertension: The assessment of combination therapy of amlodipine/ramipril (ATAR) study. Clin Ther 2008;30:18-28.

39. Chrysant SG, Melino M, Karki S, Lee J, Heyrman R. The combination of olmesartan medoxomil and amlodipine besylate in controlling high blood pressure: $\mathrm{COACH}$, a randomized, double-blind, placebocontrolled, 8-week factorial efficacy and safety study. Clin Ther 2008;30(4):587-604

40. Bisognano JD, McLaughlin T, Roberts CS, Tang SS. Calcium channel blockers, angiotensin receptor blockers, and angiotensin-converting enzyme inhibitors: Effectiveness in combination with diuretics or beta-blockers for treating hypertension. Vasc Health Risk Manag 2007;3(5):579-85

41. Maladkar M, Verma VK, Narsikar KA, Walinjkar DR, Patil WR, Saggu NJ, et al. Triple drug combination of telmisartan, amlodipine and hydrochlorothiazide in the treatment of essential hypertension. Open $\mathbf{J}$ Intern Med 2012;2:67-71.

42. Oparil S, Melino M, Lee J, Fernandez V, Heyrman R. Triple therapy with olmesartan medoxomil, amlodipine besylate, and hydrochlorothiazide in adult patients with hypertension: The TRINITY multicenter, randomized, double-blind, 12-week, parallel-group study. Clin Ther $2010 \cdot 32: 1252-69$

43. Wald DS, Law M, Morris JK, Bestwick JP, Wald NJ. Combination therapy versus monotherapy in reducing blood pressure: Metaanalysis on 11,000 participants from 42 trials. Am J Med 2009;122(3):290-300.

44. Hussain A, Aqil M, Alam MS, Khan MR, Kapur P, Pillai KK. A pharmacovigilance study of antihypertensive medicines at a South Delhi hospital. Indian J Pharm Sci 2009;71:338-41.

45. Severity Assessment of ADRs. Available from: http://www. edusanjalpharmacology.blogspot.in/2012/12/severity-assessment-ofadrs.html. [Last cited on 2015 Aug 28].

46. He J, Whelton PK, Appel LJ, Charleston J, Klag MJ. Long-term effects of weight loss and dietary sodium reduction on incidence of hypertension. Hypertension 2000;35:544-9.

47. Sacks FM, Svetkey LP, Vollmer WM, Appel LJ, Bray GA, Harsha D, et al. Effects on blood pressure of reduced dietary sodium and the Dietary Approaches to Stop Hypertension (DASH) diet. DASH-Sodium Collaborative Research Group. N Engl J Med 2001;344(1):3-10

48. Vollmer WM, Sacks FM, Ard J, Appel LJ, Bray GA, Simons-Morton DG, et al. Effects of diet and sodium intake on blood pressure: Subgroup analysis of the DASH-sodium trial. Ann Intern Med 2001:135(12):1019-28

49. Kelley GA, Kelley KS. Progressive resistance exercise and resting blood pressure: A meta-analysis of randomized controlled trials. Hypertension 2000;35(3):838-43. 